\title{
Radiological staging of rectal cancer in a resource limited setting
}

\author{
Naradha Lokuhetty ${ }^{1 *} \mathbb{0}$, Suranjith L. Seneviratne ${ }^{1}$, Fathima Asma Rahman², Thanushka Marapana ${ }^{\text {, }}$ \\ Roshan Niloofa ${ }^{2}$ and Ishan De Zoysa ${ }^{1}$
}

\begin{abstract}
Objective: Current guidelines on rectal cancer (RC) management recommend pre-operative MRI for loco-regional staging and CT for staging of metastases. This allows appropriate selection of patients for chemo-radiotherapy (CRT). However, MRI is not freely available in many low-income countries. We assessed the status of pre-operative imaging for RC in Sri Lanka and evaluated the performance of CT in RC staging.

Results: A pre-tested interview-administered questionnaire was used to assess the pre-operative use of $\mathrm{MRI}$ and CT in RC. CT findings from 37 RC patients were then compared with histopathology findings. Of the 64 surgeons interviewed, 57 (89.1\%) did not request an MRI for their RC patients. Reasons cited included limited availability and long waiting times due to competing health needs. A CT was requested by all. In RC, the overall accuracy of CT for $T$ staging was $43.2 \%$ and $29.7 \%$ of T1-T2 tumours were over-staged as T3. The overall accuracy of CT for regional lymph node staging was $70.3 \%$. In summary, CT alone is not suitable for RC staging in any setting. It leads to over-staging and patients may thus receive unnecessary CRT. Steps must be taken to improve access to pre-operative MRI among Sri Lankan RC patients.
\end{abstract}

Keywords: Rectal cancer, Radiological staging, Computed tomography, Magnetic resonance imaging

\section{Introduction}

Colorectal cancer (CRC) is the third most common cancer in the world [1]. It's incidence is increasing in the South Asian region [2, 3, 4]. Rectal cancer (RC) comprises roughly one third of CRC [5]. According to international $\mathrm{RC}$ management guidelines, magnetic resonance imaging (MRI) is best for loco-regional staging and computed tomography $(\mathrm{CT})$ for metastatic staging $[6,7]$. However, it is often difficult to obtain pre-operative MRI scans for RC patients in many lower-middle income countries including Sri Lanka [8]. CT is cheaper, faster and is more widely available $[9,10]$. It is believed that surgeons who operate on RC's from such countries may not routinely request pre-operative MRI scans.

\footnotetext{
*Correspondence: naradalokuhetty@gmail.com

1 Department of Surgery, Faculty of Medicine, University of Colombo, Colombo, Sri Lanka

Full list of author information is available at the end of the article
}

The National Institute of Clinical Excellence (NICE) 2020 guideline update recommends pre-operative chemo-radiotherapy (CRT) for T3/T4 or any N, M0 RC's [11]. Neo-adjuvant treatment in RC, down-stages the disease, and reduces overall mortality and disease recurrence [12]. At the National Hospital of Sri Lanka, RC patients with $\mathrm{CT}$ stage $\mathrm{T} 3$ and $\mathrm{T} 4$ receive neo-adjuvant CRT. We assessed the status of pre-operative imaging for $\mathrm{RC}$ in Sri Lanka and evaluated the performance of CT in $\mathrm{RC}$ staging.

\section{Main Text Methodology}

A telephone survey was carried out among 64 surgeons employed in Government hospitals in Sri Lanka who operate on RC patients. A pre-tested questionnaire (see Additional file 1) was used to gather information on each surgeon's management of RC, including the 
imaging modalities used. Demographic, clinical, radiological and treatment information of 37 patients with RC managed at the University Surgical Unit were analysed and findings from CT were compared with histopathology. A Toshiba Aquilion Lightening 16 slice CT was used, with scanning done in the arterial, portovenous and delayed phases. The CT's were reported by the same specialist radiologists and staged according to the tumour-node-metastasis (TNM) criteria. All CT scans were discussed by the radiologists and surgeons at a weekly meeting prior to the release of a final report. Post-operative specimens were staged according to the American Joint Committee on Cancer Staging (AJCC) 8th TNM model by the Department of Pathology, Faculty of Medicine, University of Colombo [13]. Ethics approval was obtained from the Ethical Review Committee of the National Hospital of Sri Lanka. Simple statistics was carried out to evaluate the accuracy of CT for local tumour $(\mathrm{T})$ and regional lymph node $(\mathrm{N})$ staging of RC.

\section{Results}

Of the 64 surgeons who took part in the survey, 58 (91\%) were general surgeons and 6 (9\%) were oncology surgeons. Only $7(10.9 \%)$ requested a pre-operative staging MRI on all RC patients, whilst all surgeons requested a CT scan. The reasons given for not ordering an MRI were: limited availability (only six MRI machines are available within the Government Health service in Sri Lanka) and the long waiting times due to the prioritization of MRI's for other specialities such as Neurology.

Of the 37 patients with RC, 20 (54\%) were male. Table 1 compares $\mathrm{T}$ staging for RC. The overall accuracy of $\mathrm{CT}$ in $\mathrm{T}$ staging $\mathrm{RC}$ 's was $43.2 \%$. T3 tumours were the most accurately staged at $60 \%$. CT over and under-staged $37.8 \%(14 / 37)$ and $18.9 \%$ (7/37) RC's respectively. $29.7 \%(11 / 37)$ of $\mathrm{T} 1-\mathrm{T} 2$ tumours were over-staged as T3. T2 tumours were most over-staged followed by $\mathrm{T} 1$.

Table 1 Comparison of $\mathrm{T}$ staging for carcinoma involving the rectum

\begin{tabular}{lllll}
\hline CT Staging & \multicolumn{5}{l}{ Pathological Staging $(n=37)$} \\
\cline { 2 - 5 } & T1 $(\mathbf{n}=\mathbf{7})$ & T2 $(\mathbf{n}=\mathbf{9})$ & T3 $(\mathbf{n}=\mathbf{1 5})$ & T4 $(\mathbf{n}=\mathbf{6})$ \\
\hline $\mathrm{T} 1$ & 3 & 0 & 1 & 0 \\
$\mathrm{~T} 2$ & 0 & 2 & 2 & 1 \\
$\mathrm{~T} 3$ & 4 & 7 & 9 & 3 \\
$\mathrm{~T} 4$ & 0 & 0 & 3 & 2 \\
\hline
\end{tabular}

Table 2 Comparison of $\mathbf{N}$ staging for carcinoma involving the rectum

\begin{tabular}{llll}
\hline CT Staging & \multicolumn{2}{l}{ Pathological Staging $(n=37)$} \\
\cline { 2 - 4 } & N0 $(n=24)$ & N1 $(n=8)$ & N2 $(n=5)$ \\
\hline N0 & 18 & 1 & 3 \\
N1 & 5 & 6 & 0 \\
N2 & 1 & 1 & 2 \\
\hline
\end{tabular}

CT staging of nodal involvement is shown in Table 2. The overall accuracy of $\mathrm{CT}$ for regional lymph nodes in RC was 70.3\% (26/37). Over and under-staging of lymph nodes by CT was seen in $18.9 \%(7 / 37)$ and $10.8 \%$ $(4 / 37)$ RC's.

\section{Discussion}

We did not find CT to accurately stage RC. T1-T2 tumours were frequently over-staged as T3 by CT. This would result in nearly one-third of patients receiving unnecessary CRT. Over-staging of T1 and T2 RC's could be a result of peri-rectal fat stranding secondary to rectal inflammation or fibrosis, being interpreted as tumour infiltration [14]. $\mathrm{N}$ staging of regional lymph nodes remains a challenge for all modalities. $\mathrm{CT}$ had a moderate accuracy of $70.3 \%$ for $\mathrm{N}$ staging in RC.

At present, MRI and endo-rectal ultra sound (ERUS) are recommended as the primary staging modalities for RC $[11,15]$. In resource-limited settings, both these modalities are difficult to access. MRI enables accurate evaluation of tumour extension into the rectal wall and evaluates poor prognostic indicators such as circumferential resection margin (CRM) involvement, extra-mural vascular involvement (EMVI) and a high level of extramural spread $[16,17]$. Staging of loco-regional lymph nodes are a challenge in RC. MRI is the recommended modality for $\mathrm{N}$ staging as it can accurately assess lymph nodes in the mesorectum and pelvic side wall [17].

Surgeons in some developing countries such as Sri Lanka continue to use $\mathrm{CT}$ as the primary pre-operative imaging modality for staging $\mathrm{RC}$. The reasons cited include unavailability and long waiting times. Given that $37.8 \%$ of RC's are over-staged, a high proportion of patients may incorrectly receive CRT (and be exposed to its associated complications of enteritis, neutropenia, chronic pain, incontinence and sexual difficulties). It may also add to the healthcare costs in a developing country. In conclusion, CT cannot be relied on for accurately staging $\mathrm{RC}$. The current practice of peri-operative imaging of RC's in Sri Lanka needs to be changed. A multi-disciplinary team consisting of surgeons, radiologists, oncologists, pathologists, health administrators 
and policy makers should be convened to find ways to improve access of $\mathrm{RC}$ patients to pre-operative staging MRI's.

\section{Limitations}

A limitation of our study was the relatively low number of RC patients studied.

\section{Supplementary information}

Supplementary information accompanies this paper at https://doi. org/10.1186/s13104-020-05327-4.

Additional file 1: Figure S1. Questionnaire on Imaging in Rectal Cancer questionnaire aimed at gathering information on the imaging modalities used by Sri - Lankan surgeons for rectal cancer patients.

\section{Abbreviations}

CRC: Colorectal cancer; RC: Rectal cancer; MRI: Magnetic resonance imaging; CT: Computed tomography; NICE: The National Institute of Clinical Excellence; CRT: Chemoradiotherapy; AJCC: American Joint Committee on Cancer Staging; T:Tumour stage; N: Lymph node stage; ERUS: Endo-rectal ultrasound; CRM: Circumferential resection margin; EMVl: Extra-mural vascular invasion.

\section{Acknowledgements}

The authors wish to thank the University Surgical Unit and Pathology department of the Faculty of Medicine, University of Colombo. The authors are grate ful for the support of colleagues in the Radiology Department at the National Hospital of Sri Lanka.

\section{Authors' contributions}

NL, FAR and TM collected data, performed data analysis, drafted the manuscript. IDZ, SLS and RN conceived the study, participated in the study design and revised it critically for important intellectual content. All authors read and approved the final manuscript.

\section{Funding}

Not applicable.

\section{Availability of data and materials}

All data associated with this manuscript are available on request to the corresponding author.

\section{Ethics approval and consent to participate}

Ethics approval for this study was taken from the Ethical Review Committee of the National Hospital of Sri Lanka. Written informed consent was taken from all participating patients who ensured anonymity.

\section{Consent for publication}

Not applicable.

\section{Competing interests}

The authors declare that they have no competing interests.

\section{Author details}

${ }^{1}$ Department of Surgery, Faculty of Medicine, University of Colombo, Colombo, Sri Lanka. ${ }^{2}$ Department of Zoology and Environment Sciences, Faculty of Science, University of Colombo, Colombo, Sri Lanka.

Received: 20 August 2020 Accepted: 4 October 2020

Published online: 09 October 2020
References

1. Fact Sheets by Population. https://globocan.iarc.fr/Pages/fact_sheet s_population.aspx.

2. Chandrasinghe PC, Ediriweera DS, Hewavisenthi J, Kumarage SK, Fernando FR, Deen KI. Colorectal cancer burden and trends in a South Asian cohort: experience from a regional tertiary care center in Sri Lanka. BMC Res Notes. 2017;10:12

3. Sung JJY, Lau JYW, Goh KL, Leung WK. Increasing incidence of colorectal cancer in Asia: implications for screening. Lancet Oncol. 2005;6(11):871-6.

4. Wong MC, Ding H, Wang J, Chan PS, Huang J. Prevalence and risk factors of colorectal cancer in Asia. Intest Res. 2019:17(3):317-29.

5. Samee A, Selvasekar CR. Current trends in staging rectal cancer. World J Gastroenterol. 2011;17(7):828-34.

6. Nerad E, Lahaye MJ, Maas M, Nelemans P, Bakers FCH, Beets GL, et al. Diagnostic Accuracy of CT for local staging of colon cancer: a systematic review and meta-analysis. Am J Roentgenol. 2016;207(5):984-95.

7. Arya S, Das D, Engineer R, Saklani A. Imaging in rectal cancer with emphasis on local staging with MRI. Indian J Radiol Imaging. 2015;25(2):148-61.

8. Hill AG, Perakath B, Bissett IP. The management of rectal cancer in a resource poor environment-a review. Int J Surg. 2006;4(2):127-30.

9. Ippolito D, Drago SG, Franzesi CT, Fior D, Sironi S. Rectal cancer staging: Multidetector-row computed tomography diagnostic accuracy in assessment of mesorectal fascia invasion. World J Gastroenterol. 2016;22(20):4891-900.

10. Maizlin ZV, Brown JA, So G, Brown C, Phang TP, Walker ML, et al. Can CT replace $M R I$ in preoperative assessment of the circumferential resection margin in rectal cancer? Dis Colon Rectum. 2010;53(3):308-14.

11. NICE. Colorectal cancer (update). (C2) Preoperative radiotherapy and chemoradiotherapy for rectal cancer. NICE guideline NG151 evidence reviews. 2020. https://www.nice.org.uk/guidance/ng151/evidence/ c2-preoperative-radiotherapy-and-chemoradiotherapy-forrectal-cance r-pdf-7029391217. Accessed 20 Feb 2020

12. Abraha I, Aristei C, Palumbo I, Lupattelli M, Trastulli S, Cirocchi R, et al. Preoperative radiotherapy and curative surgery for the management of localised rectal carcinoma. Cochrane Database Syst Rev. 2018;2018:10.

13. Tong G-J, Zhang G-Y, Liu J, Zheng Z-Z, Chen Y, Niu P-P, et al. Comparison of the eighth version of the American Joint Committee on Cancer manual to the seventh version for colorectal cancer: a retrospective review of our data. World J Clin Oncol. 2018;9(7):148-61.

14. Raman SP, Chen Y, Fishman EK. Evolution of imaging in rectal cancer: multimodality imaging with MDCT, MRI, and PET. J Gastrointest Oncol. 2015;6(2):172-84

15. Benson AB, Venook AP, Al-Hawary MM, Cederquist L, Chen Y-J, Ciombor KK, et al. Rectal cancer, Version 2.2018, NCCN clinical practice guidelines in oncology. J Natl Compreh Cancer Netw. 2018;16(7):874-901.

16. Lutz MP, Zalcberg JR, Glynne-Jones R, Ruers T, Ducreux M, Arnold D, et al. Second St. Gallen European Organisation for Research and Treatment of Cancer Gastrointestinal Cancer Conference: consensus recommendations on controversial issues in the primary treatment of rectal cancer. Eur J Cancer. 2016;63:11-24.

17. MERCURY Study Group. Relevance of magnetic resonance imagingdetected pelvic sidewall lymph node involvement in rectal cancer. BJS. 2011;98(12):1798-804.

\section{Publisher's Note}

Springer Nature remains neutral with regard to jurisdictional claims in published maps and institutional affiliations. 